Article

\title{
Fabrication of GO/Cement Composites by Incorporation of Few-Layered GO Nanosheets and Characterization of Their Crystal/Chemical Structure and Properties
}

\author{
Shenghua Lv ${ }^{1, *}$, Haoyan Hu ${ }^{1}$, Jia Zhang ${ }^{2}$, Xiaoqian Luo ${ }^{1}$, Ying Lei ${ }^{1}$ and Li Sun ${ }^{1}$ \\ 1 College of Bioresources Chemical and Materials Engineering, Shaanxi University of Science and Technology, \\ Xi'an 710021, China; Huhaoyan0609@163.com (H.H.); Luoxiaoqian8889@163.com (X.L.); \\ leiying0623@163.com (Y.L.); sunli01701107@163.com (L.S.) \\ 2 College of Environment Science and Engineering, Shaanxi University of Science and Technology, \\ Xi'an 710021, China; zhangjia_789@163.com \\ * Correspondence: lvsh@sust.edu.cn; Tel.: +86-29-8613-2651; Fax: +86-29-8616-8291
}

Received: 16 November 2017; Accepted: 14 December 2017; Published: 18 December 2017

\begin{abstract}
Original graphene oxide (GO) nanosheets were prepared using the Hummers method and found to easily aggregate in aqueous and cement composites. Using carboxymethyl chitosan (CCS) as a dispersant, few-layered GO nanosheets (1-2 layers) were obtained by forming CCS/GO intercalation composites. The testing results indicated that the few-layered GO nanosheets could uniformly spread, both in aqueous and cement composites. The cement composites were prepared with GO dosages of $0.03 \%, 0.05 \%$ and $0.07 \%$ and we found that they had a compact microstructure in the whole volume. A special feature was determined, namely that the microstructures consisted of regular-shaped crystals created by self-crosslinking. The X-ray diffraction (XRD) results indicated that there was a higher number of cement hydration crystals in GO/cement composites. Meanwhile, we also found that partially-amorphous Calcium-Silicate-Hydrate (C-S-H) gel turned into monoclinic crystals. At 28 days, the $\mathrm{GO} /$ cement composites reached the maximum compressive and flexural strengths at a $0.05 \%$ dosage. These strengths were 176.64 and $31.67 \mathrm{MPa}$ and, compared with control samples, their increased ratios were $64.87 \%$ and $149.73 \%$, respectively. Durability parameters, such as penetration, freeze-thaw, carbonation, drying-shrinkage value and pore structure, showed marked improvement. The results indicated that it is possible to obtain cement composites with a compact microstructure and with high performances by introducing CCS/GO intercalation composites.
\end{abstract}

Keywords: GO nanosheets; cement composites; cement hydration crystals; mechanical properties

\section{Introduction}

Cement composites have been used for over 2000 years, while Portland cement was discovered nearly 200 years ago and has been used ever since [1,2]. Cement composites have been widely applied to various construction engineering projects. Improving the strength and durability of these composites has been a prominent research topic in their development process [3,4]. The key goals for cement-composite improvement are higher performance and longer durability $[5,6]$. There are three performance classes for cement composites: normal performance, high-performance and ultra-high performance, with respective compressive strengths of less than $100 \mathrm{MPa}, 100-150 \mathrm{MPa}$ and more than $150 \mathrm{MPa}$. All three classes have a minimum durability of 200 years [7-9]. The present research results indicate that the strength and durability of cement composites mainly depend on their microstructure. While the factors affecting a cement composite microstructure are very complex, the main ones are cement hydration products and their aggregation methods $[10,11]$. Generally, cement hydration 
products are predominantly amorphous solids with few crystals $[12,13]$. Therefore, cement composites usually exhibit an incompact microstructure with a large amount of microcracks and porosity [14,15]. The structure of a material predetermines its properties; for cement composites, a compact and even microstructure benefits the improvement of compressive strength and durability $[16,17]$. Nowadays, the main evaluation parameters of high-performance cement composites-for example, strength and durability indexes, as well as compressive strength, flexural strength, penetration, freeze-thaw, carbonation, drying-shrinkage value and pore-structure indexes-are closely related to the microstructure of the cement composites $[18,19]$. However, it is difficult to prepare the cement composites so that they exhibit a compact and even microstructure: current high-performance cement composites are mainly obtained by selecting high-quality cement, suitable supplementary cementitious materials, ultra-fine or nanoscale filling materials and high-performance reinforcing materials [20-26]. These methods result in the high cost of high-performance cement composites. There is an urgent need to find a cheap and convenient way of preparing cement composites to obtain both high performance and an absence of structural defects.

Previous studies showed that graphene oxide (GO) nanosheets can promote the formation of regular-shaped cement hydration products and an even-compact microstructure. Both of these have a repairing effect on cracks and pores, resulting in improved strength and durability [27-29]. Increasingly, research on using GO nanosheets that reinforce cement composites is receiving worldwide attention [30,31]. Many researchers have investigated the effects of dosage, chemical structure and size range of GO sheets on the cement-hydration reaction, microstructure of cement materials and mechanical properties of cement composites [32,33]. Though researchers have varying opinions on the reinforcing function of GO nanosheets [34], the common consensus is that GO can, as a nano additive, have filling, interlocking and bridgings functions between cracks and pores in cement composites and that it can promote the formation of a compact microstructure in them while visibly improving mechanical strength and durability [35-39]. In fact, the dispersion of GO nanosheets in cement composites is the most important issue for the further development and practical application of these composites. However, research on this problem is currently limited. In our research, we found that, due to strong van der Waals interactions between GO nanosheets, the latter easily agglomerate in both aqueous solution and cement paste. This results in the uneven distribution of the GO nanosheets both in its aqueous suspension solution and in cement paste, leading to the formation of an uneven microstructure that severely influences the mechanical properties and the durability of the composite. Based on a structural analysis of GO nanosheets, we posit that the preparation of individual few-layered GO nanosheets in suspension solution is the basic premise for their uniform distribution in cement composites. In previous research on cement composites, we investigated the dispersing effects of polycarboxylate superplastisizer (PCs) [40], polyacrylic acid (PAA) [41] and grafting a polymer onto dispersed GO nanosheets [42]. The results indicated that the formation of PCs/GO or PAA/GO composites cannot uniformly distribute GO nanosheets in cement composites due to poor intercalation and dispersion capacity of PCs and PAA. The results also showed that grafting a polymer onto GO nanosheets would decrease active groups on the GO nanosheets resulting in reducing the template effects, the control capacity for cement hydration products [42].

In this paper, the GO nanosheets, which can be few-layered nanosheets and uniformly distribute in cement composites, were prepared by forming carboxymethyl chitosan (CCS)/GO intercalation composites. Following this, a series of $\mathrm{GO} /$ cement composites were prepared by incorporation of CCS/GO composites and investigated their microstructure, mechanical properties and durability indexes using various techniques. Our research results contribute to the preparation of high-performance cement composites through the few-layered GO nanosheet based formation of a compact and even microstructure. 


\section{Experimental Section}

\subsection{Chemicals and Materials}

Carboxymethyl chitosan (CCS) is water-soluble and its average molecular mass $\left(M_{\mathrm{w}}\right)$ and average molecular weight $\left(M_{n}\right)$ are 23,152 and 16,573, respectively. Polycarboxylate superplasticizer (PCs) was a common commercial product, supplied by Youbang New Materials Technology Co. Ltd. (Xi'an, China), with a water-reducing ratio of $33.5 \%$. The Portland cement (P.O.42.5) was produced by Shengwei Cement Co. Ltd. (Xi'an, China). The main chemical compositions and physical parameters are shown in Table 1.

Table 1. Chemical and mineral compositions of the Portland cement P.O.42.5.

\begin{tabular}{cccc}
\hline Chemical Components & Content (\%) & Mineral Compositions & Content (\%) \\
\hline Calcium oxide $(\mathrm{CaO})$ & 63.15 & Tricalcium silicate $\left(\mathrm{C}_{3} \mathrm{~S}, 3 \mathrm{CaO} \cdot \mathrm{SiO}_{2}\right)$ & 50.65 \\
Silicon dioxide $\left(\mathrm{SiO}_{2}\right)$ & 21.21 & Dicalcium silicate $\left(\mathrm{C}_{2} \mathrm{~S}, 2 \mathrm{CaO} \cdot \mathrm{SiO}_{2}\right)$ & 20.32 \\
luminum oxide $\left(\mathrm{Al}_{2} \mathrm{O}_{3}\right)$ & 6.35 & Dicalcium aluminate $\left(\mathrm{C}_{3} \mathrm{~A}, 3 \mathrm{CaO} \cdot \mathrm{Al}_{2} \mathrm{O}_{3}\right)$ & 15.63 \\
Ferric oxide $\left(\mathrm{Fe}_{2} \mathrm{O}_{3}\right)$ & 3.34 & Tetracalciumaluminoferrite $\left(\mathrm{C}_{4} \mathrm{AF}, 4 \mathrm{CaO} \mathrm{Al}_{2} \mathrm{O}_{3} \cdot \mathrm{Fe}_{2} \mathrm{O}_{3}\right)$ & 8.35 \\
Alkalis $\left(\mathrm{Na}_{2} \mathrm{O}\right.$ equivalent) & 1.45 & Gypsum $\left(\mathrm{SCH}_{2}, \mathrm{CaSO}_{4} \cdot 2 \mathrm{H}_{2} \mathrm{O}\right)$ & 4.27 \\
Magnesium oxide $(\mathrm{MgO})$ & 2.75 & $\mathrm{f}-\mathrm{CaO}$ & 0.78 \\
Potassium oxide $\left(\mathrm{K}_{2} \mathrm{O}\right)$ & 1.22 & & \\
Sulfur trioxide $\left(\mathrm{SO}_{3}\right)$ & 0.53 & & \\
\hline
\end{tabular}

\subsection{Preparation of GO Nanosheets Suspension}

A $1000 \mathrm{~mL}$ round flask was placed in an ice bath at $3-5{ }^{\circ} \mathrm{C}$ and $3 \mathrm{~g}$ of graphite, $70 \mathrm{~g}$ of concentrated $\mathrm{H}_{2} \mathrm{SO}_{4}$ and $2 \mathrm{~g}$ of $\mathrm{NaNO}_{3}$ were added and mixed thoroughly. Then, $11 \mathrm{~g}$ of $\mathrm{KMnO}_{4}$ was gradually added to the flask over a $60 \mathrm{~min}$ period with stirring, kept at $3-5^{\circ} \mathrm{C}$ for $1.5 \mathrm{~h}$ and at $35^{\circ} \mathrm{C}$ for $5-6 \mathrm{~h}$. After this, $120 \mathrm{~mL}$ of deionized water was added and kept at $80^{\circ} \mathrm{C}$ for $1.5 \mathrm{~h}$, following which $25 \mathrm{~g}$ of $\mathrm{H}_{2} \mathrm{O}_{2}$ was dripped into the flask over a 30 min period. The final product was purified by centrifugation, precipitation and repeated washing using deionized water until the $\mathrm{pH}$ of the washing water was 7.0. The graphite oxide was further treated with ultrasonic processing for $60 \mathrm{~min}$. The final, original GO nanosheets suspension was obtained; the control GO content was $0.5 \%$ and the $\mathrm{pH}$ value was 7.0.

\subsection{Planning and Preparation of GO/Cement Composites}

The GO/cement composites consisted of cement, sand, water, PCs, CCS and GO nanosheets with the distribution shown in Table 2. The dosages of GO, CCS and PCs were solid dosage. The PCs and GO used in this study were a PCs solution and GO nanosheets suspension solution. Their water contents counted toward the total water weight. The preparation procedure consisted in first mixing water, the CCS solution and the GO suspension solution, before treating the mixture with ultrasonication for $50 \mathrm{~min}$ in order to prepare the CCS/GO intercalation composites. Next, the cement, sand and PCs were added to the CCS/GO intercalation composites and stirred so as to prepare the GO/cement composites. The fresh cement paste was poured into different molds to prepare test samples. After $24 \mathrm{~h}$, the samples were removed from their molds and cured at $20{ }^{\circ} \mathrm{C}$ and $90 \%$ relative humidity prior to testing.

The cement composite samples included the hardened cement paste and mortar. For convenience of analysis and discussion following, using $\mathrm{S}_{1}$ present cement paste without GO; using $\mathrm{S}_{2}, \mathrm{~S}_{3}$ and $\mathrm{S}_{4}$ present cement paste with $0.03 \%, 0.05 \%$ and $0.07 \%$ GO dosage, respectively; using $\mathrm{S}_{5}$ and $\mathrm{S}_{6}$ present mortar with $0.05 \%$ GO dosage and without GO, respectively.

We investigated the effects of GO nanosheets on cement composites by incorporating CCS/GO composites into the cement paste and the mortar, separately. Our initial evaluation criterion was the compressive and flexural strength after 28 days. First, we looked at the effect of the GO dosages on the strength of the hardened cement paste by doping $0.03 \%, 0.05 \%$ and $0.07 \%$ GO nanosheets. 
The compressive and flexural strength reached the maximum value at a $0.05 \%$ GO dosage. Then, we designed the mortar with this $0.05 \%$ dosage and investigated its performance.

Table 2. Components and ratios of cement composites.

\begin{tabular}{|c|c|c|c|c|c|c|c|c|c|}
\hline \multirow{2}{*}{ Samples } & \multicolumn{6}{|c|}{ Component and Composition (Weight) } & \multirow{2}{*}{$\begin{array}{l}\text { Density } \\
\left(\mathrm{g} / \mathrm{cm}^{3}\right)\end{array}$} & \multicolumn{2}{|c|}{ Strength (MPa) } \\
\hline & Cement & Sand & Water & PCs & CCS & GO & & Compressive & Flexural \\
\hline $\mathrm{S}_{1}$ & 100 & 0 & 20 & 0.6 & 1.0 & 0 & 2.26 & 116.53 & 10.68 \\
\hline $\mathrm{S}_{2}$ & 100 & 0 & 20 & 0.6 & 1.0 & 0.03 & 2.28 & 149.36 & 22.82 \\
\hline $\mathrm{S}_{3}$ & 100 & 0 & 20 & 0.6 & 1.0 & 0.05 & 2.29 & 175.64 & 31.67 \\
\hline $\mathrm{S}_{4}$ & 100 & 0 & 20 & 0.6 & 1.0 & 0.07 & 2.31 & 166.23 & 26.38 \\
\hline $\mathrm{S}_{5}$ & 100 & 80 & 20 & 0.6 & 1.0 & 0.05 & 2.35 & 155.46 & 29.65 \\
\hline $\mathrm{S}_{6}$ & 100 & 80 & 20 & 0.6 & 1.0 & 0 & 2.33 & 128.63 & 21.26 \\
\hline
\end{tabular}

\subsection{Test Methods}

The chemical structure of GO nanosheets was tested using a Bruker EQUINOX-55 Fourier-transform infrared spectroscopy (FTIR, Ettlingen, Germany) and a Kratos XSAM 800 XPS (Manchester, UK). The test samples were repeatedly washed to remove any other components.

The micromorphology of the GO nanosheets was measured using an SPI3800N/SPA400 AFM (Osaka, Japan). The samples were a pure single component. They were prepared by putting a drop of GO-suspension solution (0.5\% GO was diluted 1000-2000 times) on a piece of monocrystalline silicon and drying it naturally. The three-dimensional shape of the GO nanosheets was obtained from the atomic force microscopy (AFM) images. The GO nanosheets' size distribution in the suspension was obtained using a NANO-ZS90 laser particle analyzer (LPA, Worcestershire, UK). The x-ray powder diffraction (XRD) patterns of the GO and CCS/GO composites were obtained using a D/max 2200PC $\mathrm{x}$-ray diffraction machine (XRD, Osaka, Japan) and the samples were prepared by freeze drying $0.5 \%$ of the original GO nanosheets suspension and CCS/GO composites.

The microstructure of the GO/cement composites was tested using a Hitachi S-4800 SEM (Tokyo, Japan). The test samples were dried and coated with gold for conductivity. The pore structure of the GO/cement composites was tested using an Autopore IV9500 automatic mercury porosimeter (Norcross, GA, USA). The samples were approximately $1 \mathrm{~cm}$ large. They were dried before being accurately weighed and placed in an expansion joint. They were then sealed and tested at low pressure (0-30 MPa) and then at high pressure (30-400 MPa). The crystalline structure of the composites was tested using the same XRD tester. For the $S_{5}$ and $S_{6}$ samples, the sand in the composites was removed for XRD testing.

The compressive strength of GO/cement composites was tested using a JES-300 concrete compressive strength tester (Wuxi, China) with an increase rate of 2.4-2.6 MPa/s. The flexural strength was determined using a DKZ-500 concrete three-point flexural strength tester (Wuxi, China) with an increase rate of $1 \mathrm{MPa} / \mathrm{s}$. We tested five samples for each cement composite recipe. The test results were evaluated using standard deviation.

The durability parameters such as water-penetration resistance, freeze-thawing resistance, carbonation resistance and drying-shrinkage value were measured according to GB/T5082-2009.

\section{Results and Discussion}

\subsection{Chemical Structure and Microstructure of GO Nanosheets}

The test results of the chemical structure and size distribution of the GO nanosheets are shown in Figure 1. Figure 1a shows the FTIR spectra of the graphite, GO, CCS and CCS/GO. The results of GO indicate that there are chemical groups of $\mathrm{C}=\mathrm{C}\left(1621 \mathrm{~cm}^{-1}\right), \mathrm{C}-\mathrm{OH}\left(3400 \mathrm{~cm}^{-1}\right), \mathrm{C}-\mathrm{O}-\mathrm{C}(1261$ and $\left.1061 \mathrm{~cm}^{-1}\right), \mathrm{C}=\mathrm{O}$ and $\mathrm{COOH}\left(1730 \mathrm{~cm}^{-1}\right)$. The characteristic groups of CCS are $3400 \mathrm{~cm}^{-1}(-\mathrm{OH}$ and $\left.-\mathrm{NH}_{2}\right), 1678 \mathrm{~cm}^{-1}(-\mathrm{C}=\mathrm{O})$ and 1420,1180 and $1050 \mathrm{~cm}^{-1}(-\mathrm{O}-)$. The results also confirmed that the CCS/GO contain these characteristic functional groups in both the CCS and GO, whose included 
peaks are at $3400 \mathrm{~cm}^{-1}\left(-\mathrm{OH}\right.$ and $\left.-\mathrm{NH}_{2}\right), 1728 \mathrm{~cm}^{-1}(-\mathrm{COOH}), 1628,1420,1190$ and $1310 \mathrm{~cm}^{-1}$ (-NHCO-) and $1060 \mathrm{~cm}^{-1}$ (-O-). FTIR spectra thereby prove that the CCS/GO samples contain both CCS and GO. Figure $1 \mathrm{~b}$ shows the $\mathrm{x}$-ray photoelectron spectroscopy (XPS) spectra of GO, suggesting that it also contains $\mathrm{C}=\mathrm{C} / \mathrm{C}-\mathrm{C}, \mathrm{C}-\mathrm{O} / \mathrm{C}-\mathrm{O}-\mathrm{C}$ and $-\mathrm{C}=\mathrm{O}$ groups, with proportions of $41.03 \%, 3.99 \%$, $22.52 \%$ and $32.46 \%$, respectively. Figure $1 \mathrm{c}$ shows the size range of GO nanosheets obtained through LPA. The results indicate that the size range of GO nanosheets in CCS/GO composites is $2-380 \mathrm{~nm}$, while the size range in the original GO suspension solution is $12-550 \mathrm{~nm}$. The size range has clearly decreased as a result of the formation of CCS/GO intercalation composites. The main reason for the difference between two GO nanosheets is that the GO nanosheets in CCS/GO composites have been separated as individual few-layered nanosheets due to CCS penetrating into interlayers of GO nanosheets and extending the interlayer space. Figure $1 \mathrm{~d}$ shows the XRD patterns for graphite, GO and CCS/GO. The intensity and shape of the peaks have a decreasing tendency from graphite through GO to CCS/GO. The interlayer spaces of the GO nanosheets increase from $0.35 \mathrm{~nm}$ of graphite to $0.73 \mathrm{~nm}$ of $\mathrm{GO}$ and $0.83 \mathrm{~nm}$ of CCS/GO. The results suggest that the decreased regularity of the graphite sheets is due to the oxidation and intercalation of CCS. This introduced oxygen functional groups via oxidation before inserting CCS polymer chains into the GO interlayers via intercalation, resulting in the increased interlayer spaces and the weakened interaction of the interlayers. The synergy between oxidation reaction and CCS intercalation will therefore contribute to enlarging interlayer spaces and will, to the best of its abilities, distribute the few-layered nanosheets uniformly and individually throughout the aqueous composite.
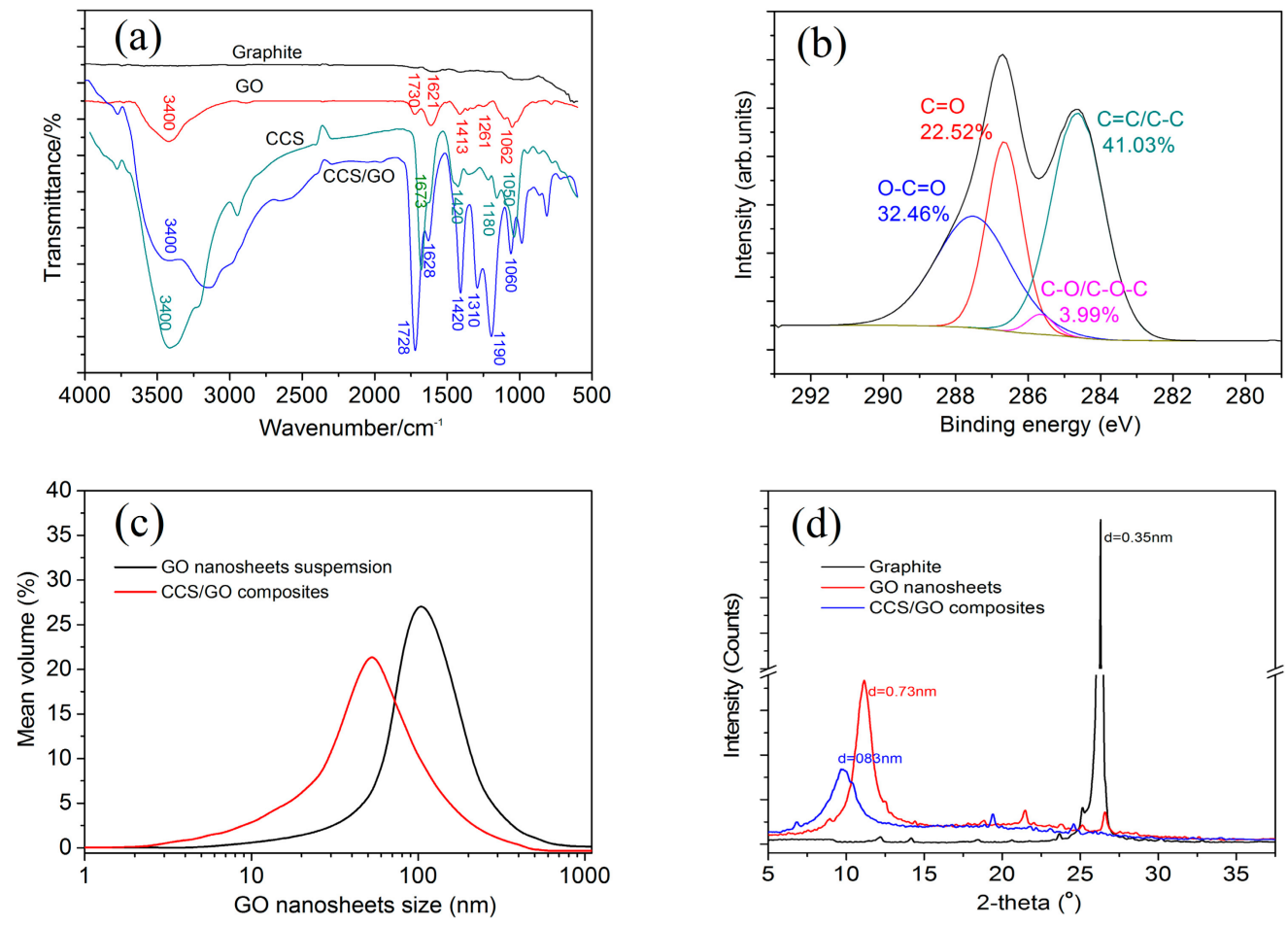

Figure 1. Test results of graphene oxide (GO) nanosheets. (a) Fourier transform infrared spectroscopy (FTIR) spectra; (b) X-ray photoelectron spectroscopy (XPS) spectra; (c) size ranges; and (d) X-ray diffraction (XRD) patterns of GO nanosheets.

The microstructures of GO nanosheets are shown in Figure 2. Figure 2a,d exhibit the planar morphology of the original GO nanosheets and CCS/GO composites in a clear way. The size ranges of the GO nanoshets in Figure 2a,d were 200-980 and 50-450 nm, respectively. The results suggest that original GO nanosheets are larger when compared to the CCS/GO composites. The three-dimensional (3D) morphology in Figure 2b,e indicate that the original GO nanosheets have a dense and flat 
morphology, while the CCS/GO composites have a puffy appearance, flattening uneven surfaces. Figure 2c,f are profile views of GO and CCS/GO and their thicknesses are about 19.87, 8.43, 1.98 and $1.12 \mathrm{~nm}$ each. Given that their corresponding interlayer spaces are, respectively, 0.73 and $0.85 \mathrm{~nm}$, their thicknesses consisted respectively of 16, 7, 2 and 1 layer of single GO nanosheets $(0.35 \mathrm{~nm})$. These results therefore confirm that GO nanosheets in CCS/GO composites can be few-layered (fewer than 3 layers) and uniformly and individually distributed in the aqueous composite solution. Our results suggest that GO nanosheets have an even dispersion in CCS/GO intercalation composites.
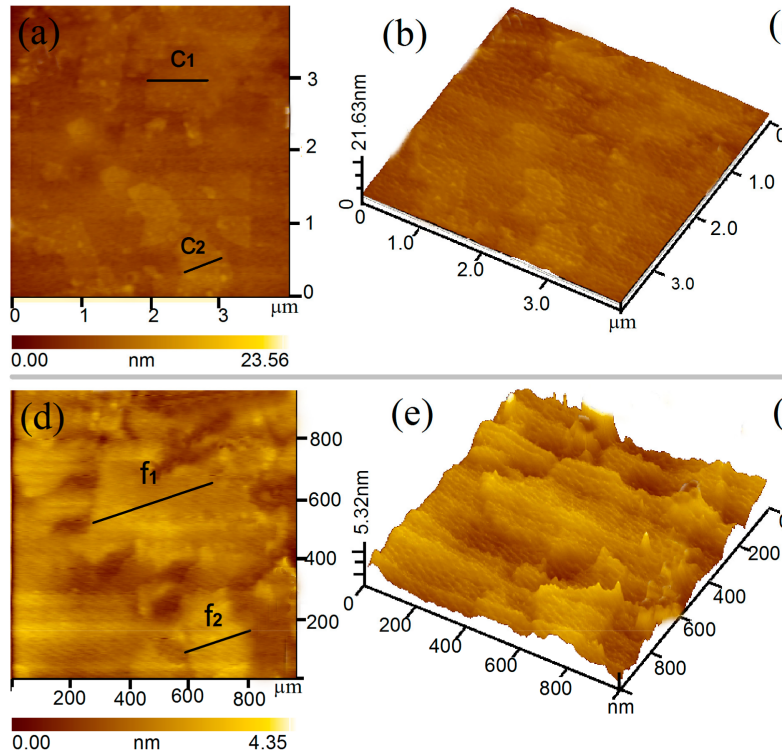

(e) (c)
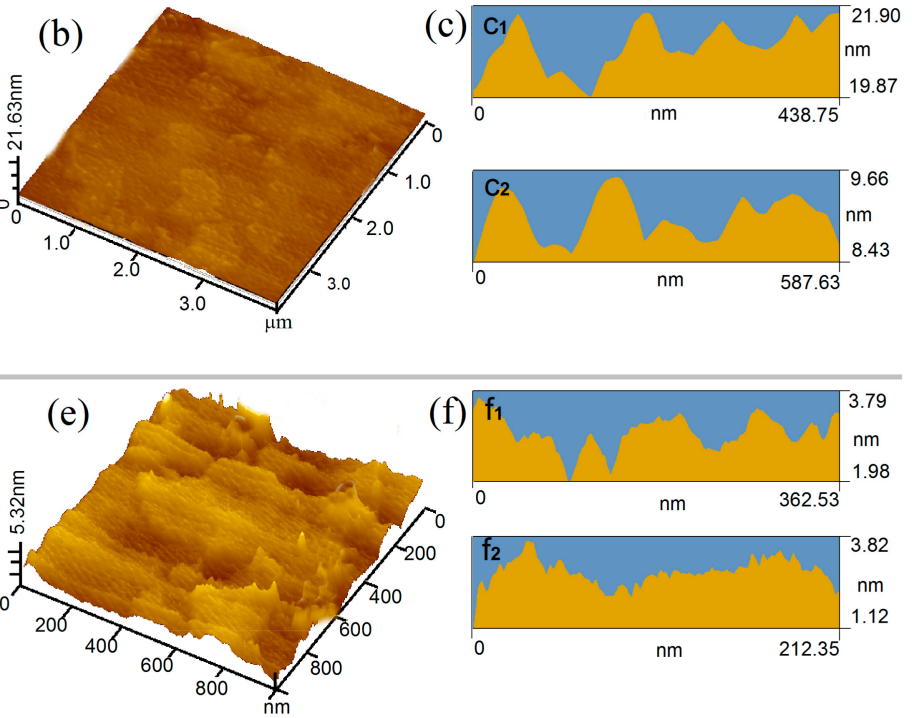

(f) $f_{1}$

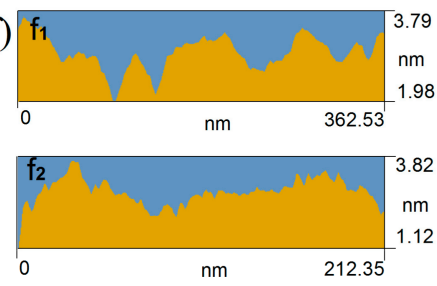

Figure 2. Atomic force microscopy (AFM) images of GO nanosheets: (a) from original GO nanosheets; (b) three-dimensional images; (c) profile images; (d) from carboxymethyl chitosan (CCS)/GO intercalation composites; (e) three-dimensional images and (f) profile images.

The above results indicate that GO nanosheets can disperse into 1 or 2 single layers by forming CCS/GO intercalation composites. The structure of CCS contains carboxyl groups and amine groups, which exhibit an amphoteric character. CCS has a potentially high adsorption capacity due to its positive amino groups. We show a possible working mechanism for CCS/GO intercalation in Figure 3. Figure 3a shows that graphite that is oxidized by a strong oxidizer will transfer into graphite oxide. Figure $3 \mathrm{~b}$ shows the expansion of graphite due to chemical groups grafted on the graphite surface and the edges and the swelling first occurs at the edges. In the original GO nanosheets suspension, the GO nanosheets struggled to survive as single and individual GO nanosheets because of self-agglomeration and of the stronger interaction in the layers (Figure 3c). When CCS is added to a GO nanosheets suspension, it can penetrate the GO nanosheets and form an action between the GO and CCS because of the multiple functional groups of $\mathrm{CCS}\left(-\mathrm{NH}_{2},-\mathrm{COOH},-\mathrm{OH}\right)$ and the $\mathrm{GO}$ surface $(-\mathrm{COOH},-\mathrm{OH})$. Moreover, CCS comprises longer chains with ring-structure units that are highly soluble. This makes it easier for them to stick to the GO nanosheets' surface, facilitating an even dispersion in the solution, thanks to both steric hindrance and electrostatic repulsion (Figure 3d). GO nanosheets therefore exist as few-layered individual nanosheets that are uniformly distributed within the suspension. 


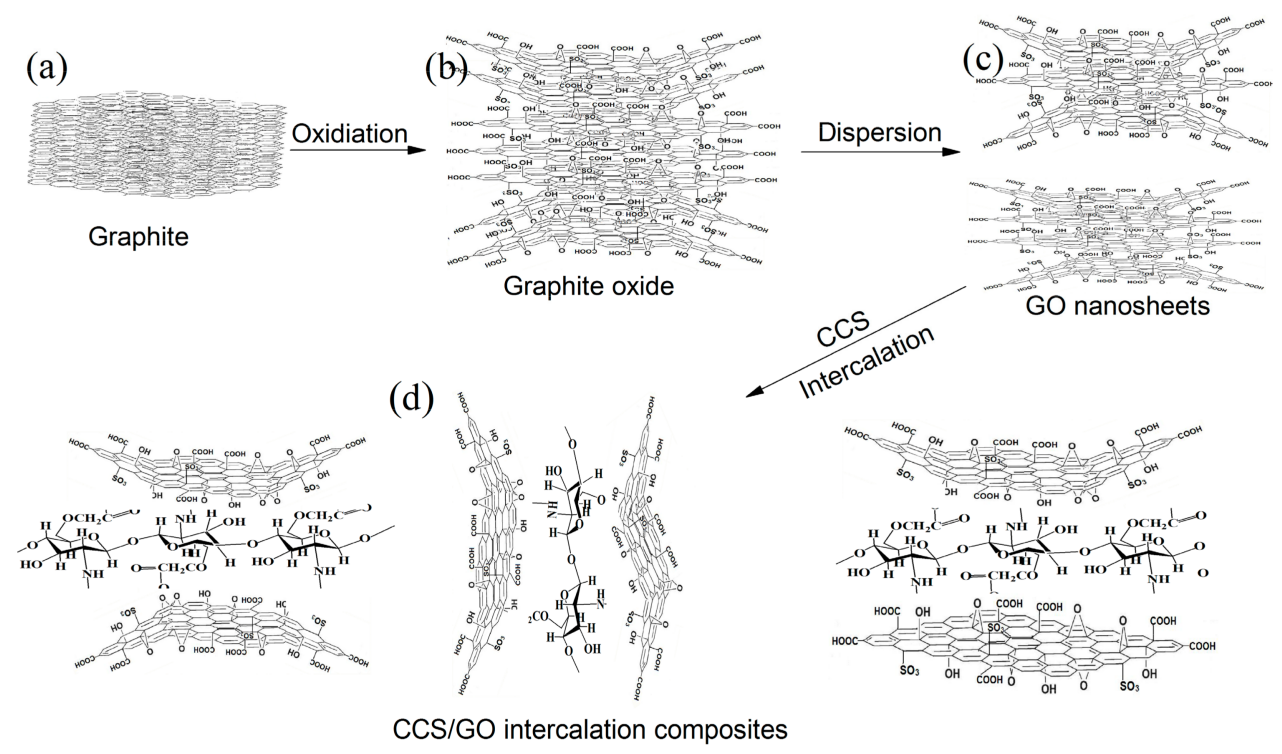

Figure 3. Formation process of CCS/GO intercalation composites. (a) Graphite; (b) Graphite oxide; (c) Graphene oxide; (d) few-layered graphene oxide nanosheets aggregation.

\subsection{Microstructure of Cement Composites}

After 28 days, the microstructure of the different cement composites was investigated using scanning electron microscopy (SEM). Figure 4 shows the corresponding SEM images. Figure 4a shows the microstructure of the $S_{1}$ sample, indicating that the microstructure is an amorphous solid with many pores and microcracks. The results indicate that cement hydration products are mainly amorphous solids that form an incompactness microstructure. Figure $4 \mathrm{~b}$ shows $\mathrm{S}_{2}$ 's microstructure, indicating that the cement composites consist of regular-shaped crystals formed by self-interweaving and self-crosslinking. The results suggest that GO can promote the production of more regular-shaped crystals and the formation of large-scale microstructure that have an even structure. Figure $4 \mathrm{c}-\mathrm{e}$ show the SEM images of $S_{3}, S_{4}$ and $S_{5}$. One can see that these cement composites also have a similar appearance and microstructure to $S_{2}$ but their crosslinking microstructure is more compact than that of $\mathrm{S}_{2}$. The results indicate that the cement composites produce a higher number of regular-shaped crystals that participate in forming the crosslinking and interweaving microstructure. This phenomenon is due to the large GO dosages in $\mathrm{S}_{3}(0.05 \% \mathrm{GO})$ and $\mathrm{S}_{4}(0.07 \% \mathrm{GO})$. Figure $4 \mathrm{f}$ shows $\mathrm{S}_{6}$ 's SEM image, where one can see that the microstructure is an amorphous solid with cracks. When compared with previous research results [24,25], the above results indicate that cement composites that are composed of $0.03 \%, 0.05 \%$ and $0.07 \%$ of GO nanosheets obtained through CCS/GO intercalation composites have a higher amount of regular-shaped crystal products and form large-scale compact microstructures. The difference between the current preparation and previous assays is that the present experiment made use of few-layered GO nanosheets, while previous experiments used more layers GO nanosheet suspensions in cement composites. GO nanosheets in CCS/GO intercalation composites are few-layered and can be uniformly and individually distributed in cement composites. This produces more regular-shaped crystals and large-scale compact microstructures through the self-interweaving and self-crosslinking of crystals. The results suggest that the dispersion of GO nanosheets in cement composites is heavily influenced to cement crystals, particularly the macrostructure of cement composites. Improving the dispersion of GO nanosheets in cement composites would certainly be beneficial to the formation of compact structures. 

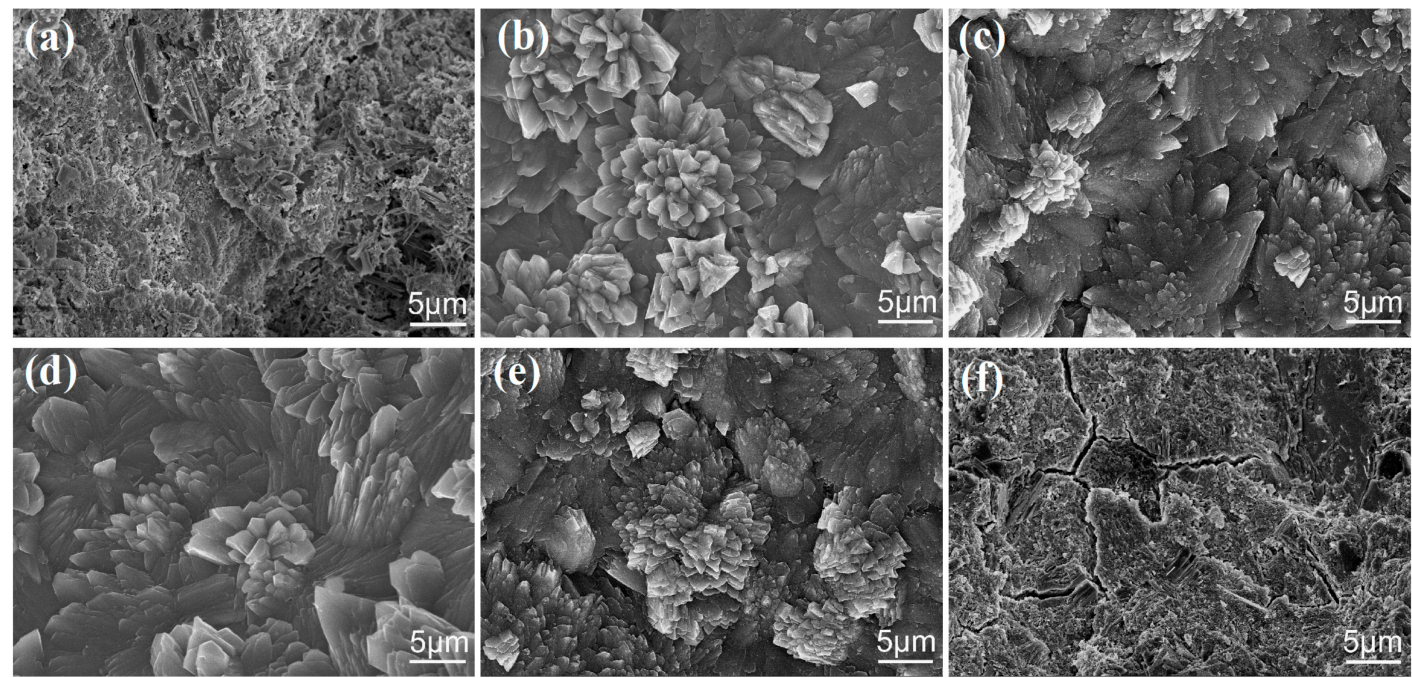

Figure 4. Scanning electron microscope (SEM) images of cement composites after 28 days. (a) $S_{1} ;$; b) $S_{2}$; (c) $\mathrm{S}_{3} ;(\mathbf{d}) \mathrm{S}_{4} ;(\mathbf{e}) \mathrm{S}_{5} ;(\mathbf{f}) \mathrm{S}_{6}$.

The above results indicate that cement composites with a compact and even microstructure can be obtained by uniformly distributing few-layered GO nanosheets in cement composites. The distribution of GO nanosheets in cement composites can be characterized by testing both the carbon mapping in a whole SEM image and the carbon content in a restricted area, using energy dispersive $x$-ray spectrometry (EDS). Figure $5 a-c$ show the SEM images of $S_{2}, S_{3}$ and $S_{4}$ samples. Figure $5 d-f$ show the carbon mapping of the corresponding whole testing area of Figure $5 \mathrm{a}-\mathrm{c}$, respectively. The results indicate that the carbon mapping is uniformly distributed within the whole testing area. They suggest that GO nanosheets with dosages of $0.03 \%, 0.05 \%$ and $0.07 \%$ can uniformly and individually spread in cement composites, resulting in the formation of even and compact microstructures in whole cement composites.
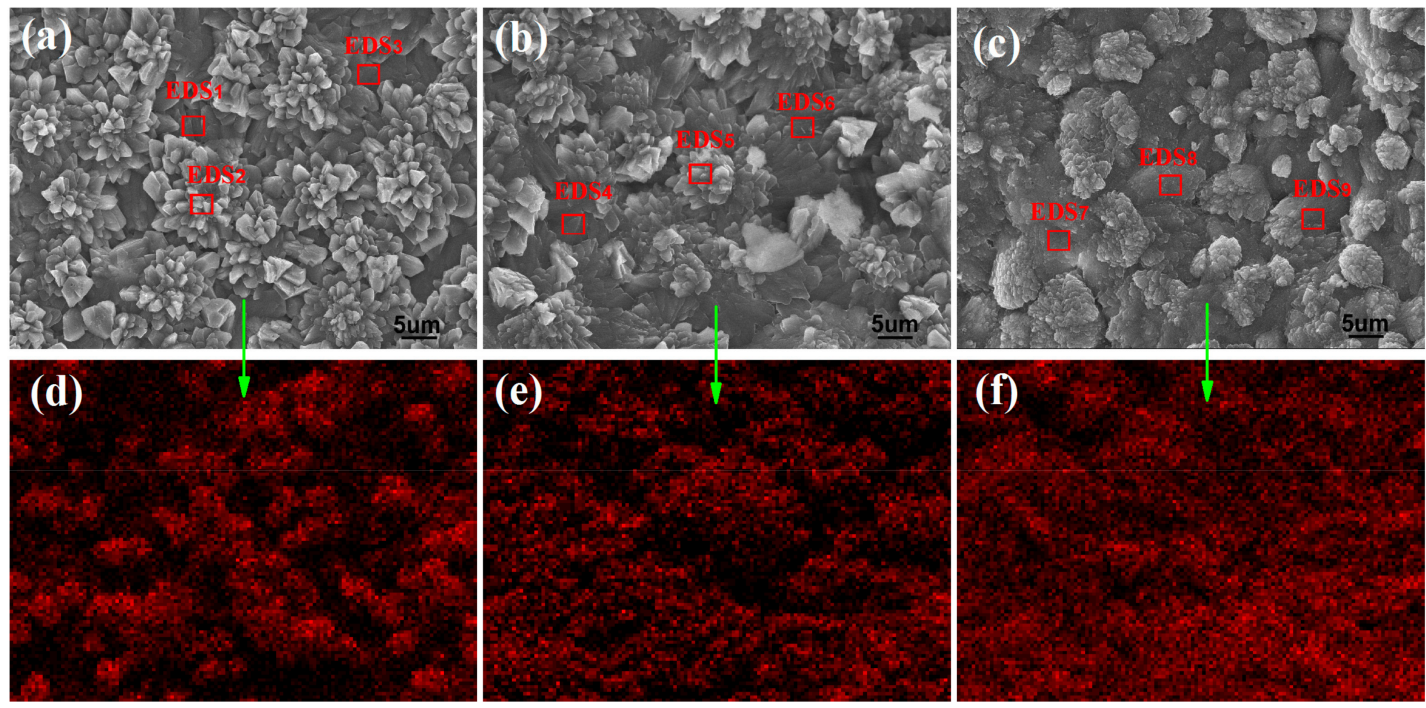

Figure 5. Carbon mapping in whole scanning electron microscopy (SEM) images. (a) $S_{2}$; (b) $S_{3}$; (c) $S_{4}$; (d-f) Carbon mapping.

The carbon content in a restricted area is shown in Table 3. The EDS testing areas are marked as red boxes in Figure 5 and the test results are shown in Table 3. The results indicate that the carbon 
content exhibits a gradual upward trend from $S_{2}$ through $S_{3}$ to $S_{4}$. The main reason for this is that the GO dosage gradually increases from $0.03 \%$ for $S_{2}$ through $0.05 \%$ for $S_{3}$ to $0.07 \%$ for $S_{4}$. The EDS test results indicate that the carbon contents in cement composites are greater than the corresponding $\mathrm{GO}$ dosages and the reason might be that the GO nanosheets are dispersed mainly in the crystal surface. Furthermore, the results indicate that the oxygen, silicon and calcium are also uniformly distributed in the testing areas according to their content, suggesting that the crystals have an even element composition and crystal phase structure. Finally, the carbon content at the center of the flower-like crystals is slightly higher than that of other parts such $\mathrm{EDS}_{2}$ and EDS 5 . The results suggest that the GO nanosheets exist mainly in initial producing crystals, located in the center position. These initial crystals may serve as a growing template for the subsequent production of further crystals. Therefore, all elements have a uniform distribution in the cement composites and this result in the production of more regular-shaped crystals and a compact microstructure.

Table 3. Elemental composition of cement matrix doped with graphene oxide (GO).

\begin{tabular}{ccccccccccc}
\hline \multirow{2}{*}{ Samples } & \multicolumn{10}{c}{ Elemental Content (wt \%) } \\
\cline { 2 - 11 } & $\mathbf{C}$ & $\mathbf{O}$ & $\mathbf{S i}$ & $\mathbf{C a}$ & $\mathbf{A l}$ & $\mathbf{M g}$ & $\mathbf{N a}$ & $\mathbf{K}$ & $\mathbf{F e}$ & $\mathbf{S}$ \\
\hline Cement & 1.34 & 34.83 & 9.63 & 44.31 & 3.52 & 1.68 & 1.13 & 0.95 & 2.38 & 0.23 \\
DES $_{1}$ & 4.28 & 39.56 & 2.26 & 46.08 & 2.94 & 1.69 & 1.02 & 0.94 & 0.97 & 0.26 \\
EDS $_{2}$ & 5.63 & 38.54 & 2.51 & 44.91 & 3.41 & 1.65 & 1.15 & 0.65 & 1.32 & 0.23 \\
EDS $_{3}$ & 4.56 & 37.56 & 2.89 & 45.62 & 3.52 & 1.68 & 1.24 & 1.34 & 1.32 & 0.27 \\
EDS $_{4}$ & 6.45 & 41.32 & 2.81 & 42.45 & 2.61 & 1.56 & 1.38 & 0.81 & 0.44 & 0.17 \\
EDS $_{5}$ & 5.52 & 42.39 & 3.21 & 43.42 & 1.42 & 1.62 & 1.25 & 0.64 & 0.34 & 0.19 \\
EDS $_{6}$ & 6.65 & 40.49 & 3.21 & 42.39 & 2.56 & 1.78 & 1.12 & 0.78 & 0.81 & 0.21 \\
DES $_{7}$ & 9.85 & 40.42 & 2.91 & 40.71 & 1.95 & 1.62 & 1.13 & 0.35 & 0.85 & 0.21 \\
EDS $_{8}$ & 10.23 & 40.56 & 2.43 & 40.15 & 2.86 & 1.45 & 1.15 & 0.27 & 0.63 & 0.27 \\
EDS $_{9}$ & 9.94 & 40.55 & 2.35 & 40.81 & 1.98 & 1.68 & 1.35 & 0.35 & 0.76 & 0.23 \\
\hline
\end{tabular}

\subsection{Crystal Structure of Cement Hydration Crystals}

The above results indicate that cement hydration products can be converted into regular-shaped crystals and that they form a compact microstructure by doping GO nanosheets. These results are a significant departure from the traditional view on cement hydration products. The main components of cement are $\mathrm{C}_{3} \mathrm{~S}, \mathrm{C}_{2} \mathrm{~S}, \mathrm{C}_{3} \mathrm{~A}, \mathrm{C}_{4} \mathrm{AF}$ and $\mathrm{SCH}_{2}$. It can react with water to produce hydration products of ettringite (AFt) $\left[\left(\mathrm{Ca}_{6} \mathrm{Al}_{2}\left(\mathrm{SO}_{4}\right)_{3}\right)(\mathrm{OH})_{12} \cdot 26 \mathrm{H}_{2} \mathrm{O}\right]$, monosulfate $(\mathrm{AFm})\left[\mathrm{Ca}_{4} \mathrm{Al}_{2}(\mathrm{OH})_{2} \cdot \mathrm{SO}_{4} \cdot \mathrm{H}_{2} \mathrm{O}\right]$, calcium hydroxide $(\mathrm{CH})\left[\mathrm{Ca}(\mathrm{OH})_{2}\right]$, and calcium silicate hydrate $(\mathrm{C}-\mathrm{S}-\mathrm{H})[3 \mathrm{CaO} \cdot 2 \mathrm{SiO} 2 \cdot 3 \mathrm{H} 2 \mathrm{O}]$, gel. Generally, these hydration products can exhibit various shapes and form irregular aggregations, resulting in the formation of a microstructure with cracks and pores. The crystal structure of cement hydration products was measured using XRD.

The XRD patterns of the cement composites are shown in Figure 6 and the analytical results are shown in Table 4. The results indicate that the cement hydration products in $\mathrm{S}_{1}$ (cement composites without $\mathrm{GO}$ nanosheets) are mainly $\mathrm{CH}, \mathrm{CaCO}_{3}, \mathrm{AFt}, \mathrm{AFm}, \mathrm{C}-\mathrm{S}-\mathrm{H}$, $\mathrm{CaAl}_{2} \mathrm{Si}_{6} \mathrm{O}_{16} \cdot 6 \mathrm{H}_{2} \mathrm{O}, \mathrm{Ca}_{6}\left(\mathrm{AlSiO}_{4}\right)_{12} \cdot 30 \mathrm{H}_{2} \mathrm{O}$ and $\mathrm{CaHSi}_{2} \mathrm{O}_{7}$. These products mainly exhibit crystal structure, and most products are amorphous solids and a lesser amount of regular shaped crystals. Therefore, $S_{1}$ as a whole exhibits an amorphous solid. For the GO/cement composites of $S_{2}$ $(0.03 \% \mathrm{GO}), \mathrm{S}_{3}(0.05 \% \mathrm{GO})$ and $\mathrm{S}_{4}(0.07 \% \mathrm{GO})$, there are more cement hydration crystal products, such as $\mathrm{CH}, \mathrm{CaCO}_{3}, \mathrm{AFt}, \mathrm{AFm}, \mathrm{C}-\mathrm{S}-\mathrm{H}, \mathrm{CaAl}_{2} \mathrm{Si}_{6} \mathrm{O}_{16} \cdot 6 \mathrm{H}_{2} \mathrm{O}, \mathrm{Ca}_{6}\left(\mathrm{AlSiO}_{4}\right)_{12} \cdot 30 \mathrm{H}_{2} \mathrm{O}, \mathrm{CaHSi}_{2} \mathrm{O}_{7}$, $\mathrm{Ca}_{3} \mathrm{Si}(\mathrm{OH})_{6}\left(\mathrm{CO}_{3}\right)\left(\mathrm{SO}_{4}\right) \cdot 12 \mathrm{H}_{2} \mathrm{O}, \quad \mathrm{Ca}_{4} \mathrm{Si}_{4} \mathrm{O}_{4}(\mathrm{OH})_{24} \cdot 3 \mathrm{H}_{2} \mathrm{O}, \mathrm{Ca}_{5} \mathrm{Si}_{16} \mathrm{O}_{16}(\mathrm{OH})_{2}, \quad \mathrm{~K}_{2} \mathrm{Ca}_{5}\left(\mathrm{SO}_{4}\right)_{6} \cdot \mathrm{H}_{2} \mathrm{O}$, $\mathrm{Ca}_{2} \mathrm{Al}_{2} \mathrm{Fe}_{2} \mathrm{O}_{5}$ and $\mathrm{Ca}_{3} \mathrm{Si}(\mathrm{OH})_{6}\left(\mathrm{CO}_{3}\right)\left(\mathrm{SO}_{4}\right) \cdot 12 \mathrm{H}_{2} \mathrm{O}$. The crystals exhibit hexagonal, cubic and tetragonal crystal structures. As they are similar to $S_{4}$ and $S_{1}$ respectively, the XRD patterns of $S_{5}$ and $S_{6}$ and their analysis results are not listed here.

Additionally, the intensity of crystal peaks in Figure 6 gradually increases with the GO dosage, from $0.03 \%\left(\mathrm{~S}_{2}\right)$ through $0.05 \%\left(\mathrm{~S}_{3}\right)$ to $0.07 \%\left(\mathrm{~S}_{4}\right)$, which suggests that the control capacity of GO 
nanosheets is closely related to the GO dosage. The crystal integrity and the peak intensity show an upward trend from $S_{2}$ through $S_{3}$ to $S_{4}$. We also found that the amorphous C-S-H gel can turn into monoclinic crystals in $S_{2}, S_{3}$ and $S_{4}$. The results indicate that GO nanosheets can turn cement hydration products into regular-shaped crystals and form compact microstructures.
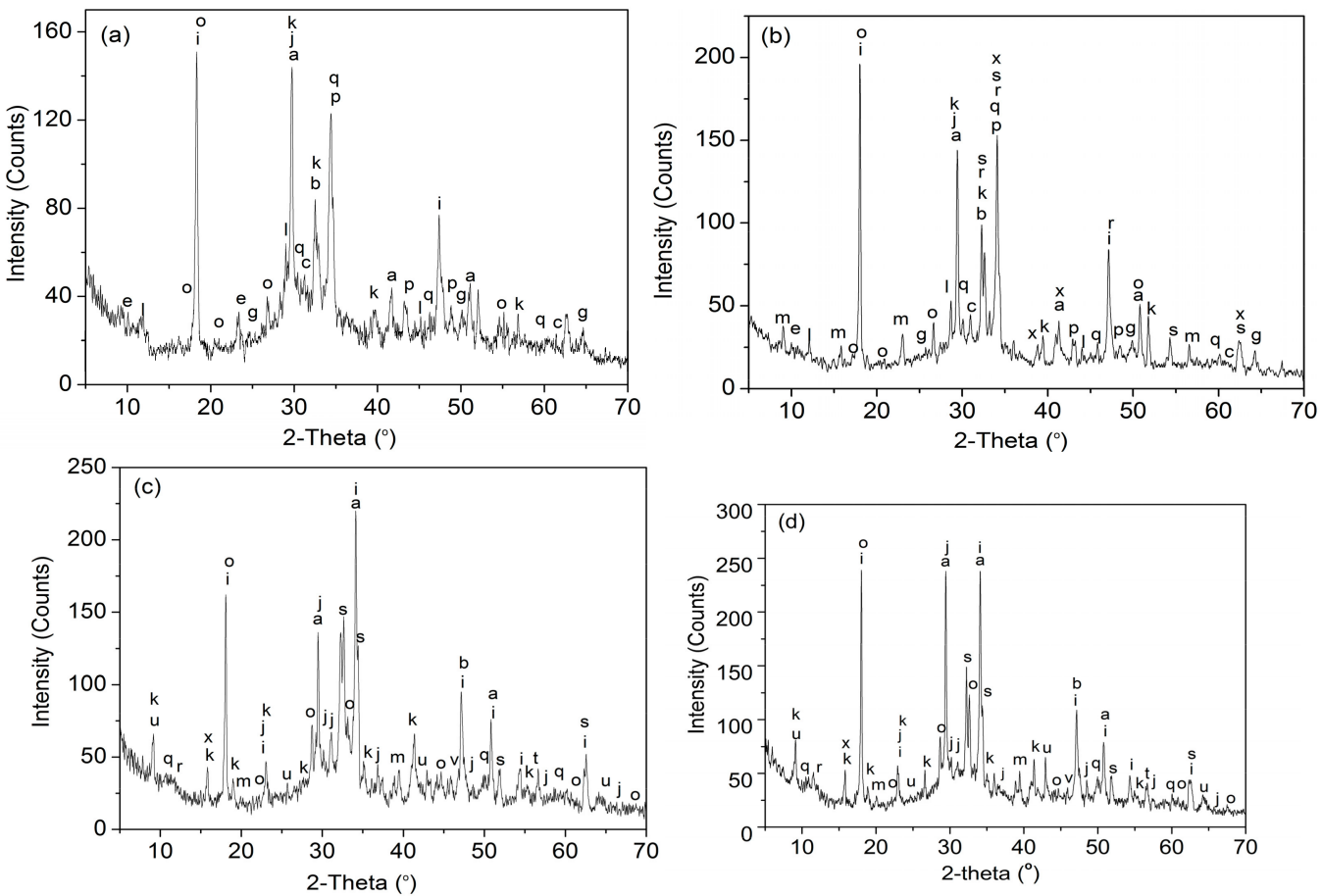

Figure 6. X-Ray Diffraction (XRD) patterns of cement composites at 28 days: (a) $S_{1} ;$ (b) $S_{2} ;$ (c) $S_{3} ;$ (d) $S_{4}$.

Table 4. Crystal phases of cement composites.

\begin{tabular}{|c|c|c|c|c|c|}
\hline \multirow{2}{*}{ Hydration Products } & \multirow{2}{*}{ Crystal System } & \multicolumn{4}{|c|}{ Cement Composites * } \\
\hline & & $\mathrm{S}_{1}$ & $\mathrm{~S}_{2}$ & $\mathrm{~S}_{3}$ & $\mathrm{~S}_{4}$ \\
\hline $\mathrm{C}_{3} \mathrm{~S}, \mathrm{Ca}_{2} \mathrm{SiO}_{5}$ & Monoclinic & + & + & + & + \\
\hline $\mathrm{C}_{2} \mathrm{~S}, \mathrm{Ca}_{2} \mathrm{SiO}_{4}$ & Monoclinic & + & + & + & + \\
\hline $\mathrm{C}_{3} \mathrm{~A}, \mathrm{Ca}_{3} \mathrm{Al}_{2} \mathrm{O}_{6}$ & Orthorhombic & + & + & & \\
\hline $\mathrm{C}_{4} \mathrm{AF}_{2} \mathrm{Ca}_{4} \mathrm{Al}_{2} \mathrm{Fe}_{2} \mathrm{O}_{10}$ & Tetrahedral & + & & & \\
\hline $\mathrm{CaSO}_{4} \cdot 2 \mathrm{H}_{2} \mathrm{O}$ & Monoclinic & + & & & \\
\hline $\mathrm{Al}_{2} \mathrm{O}_{3}$ & Hexagonal & & & & \\
\hline $\mathrm{SiO}_{2}$ & Tetragonal & + & + & + & + \\
\hline $\mathrm{CaO}$ & Cubic & & & & \\
\hline $\mathrm{Ca}(\mathrm{OH})_{2}$ & Hexagonal & + & + & + & + \\
\hline $\mathrm{CaCO}_{3}$ & Hexagonal & + & + & + & + \\
\hline $\mathrm{AFt}, \mathrm{Ca}_{6} \mathrm{Al}_{2}\left(\mathrm{SO}_{4}\right)_{3}(\mathrm{OH})_{12} \cdot 26 \mathrm{H}_{2} \mathrm{O}$ & Hexagonal & + & + & + & + \\
\hline $\left.\mathrm{AFm}, \mathrm{Ca}_{4} \mathrm{Al}_{2} \mathrm{O}_{6}\left(\mathrm{SO}_{4}\right) \cdot 14 \mathrm{H}_{2} \mathrm{O}\right)$ & Hexagonal & + & + & + & + \\
\hline $\left.\mathrm{C}-\mathrm{S}-\mathrm{H}, \mathrm{Ca}_{3} \mathrm{Si}_{2} \mathrm{O}_{7} \cdot \mathrm{xH}_{2} \mathrm{O}\right)$ & Amorphous & + & + & + & + \\
\hline $\mathrm{C}-\mathrm{S}-\mathrm{H}\left(\mathrm{Ca}_{3} \mathrm{Si}_{2} \mathrm{O}_{7} \cdot \times \mathrm{H}_{2} \mathrm{O}\right)$ & Monoclinic & & + & + & + \\
\hline $\mathrm{CaAl}_{2} \mathrm{Si}_{6} \mathrm{O}_{16} \cdot 6 \mathrm{H}_{2} \mathrm{O}$ & Tetragonal & + & + & + & + \\
\hline $\mathrm{Ca}_{2} \mathrm{H}_{2} \mathrm{Si}_{2} \mathrm{O}_{7}$ & Orthorhombic & + & & + & + \\
\hline $\mathrm{Ca}_{6}\left(\mathrm{AlSiO}_{4}\right)_{12} \cdot 30 \mathrm{H}_{2} \mathrm{O}$ & Cubic & + & + & + & + \\
\hline $\mathrm{Ca}_{4} \mathrm{Si}_{4} \mathrm{O}_{4}(\mathrm{OH})_{24} \cdot 3 \mathrm{H}_{2} \mathrm{O}$ & Monoclinic & & + & + & + \\
\hline $\mathrm{Ca}_{3} \mathrm{Si}(\mathrm{OH})_{6}\left(\mathrm{CO}_{3}\right)\left(\mathrm{SO}_{4}\right) 12 \mathrm{H}_{2} \mathrm{O}$ & Hexagonal & & + & + & + \\
\hline $\mathrm{K}_{2} \mathrm{Ca}_{5}\left(\mathrm{SO}_{4}\right)_{6} \cdot \mathrm{H}_{2} \mathrm{O}$ & Monoclinic & & & + & + \\
\hline $\mathrm{CaFe}_{5} \mathrm{AlO}_{10}$ & Tetragonal & & + & + & + \\
\hline $\mathrm{Ca}_{2} \mathrm{Al}_{2} \mathrm{Fe}_{2} \mathrm{O}_{8}$ & Orthorhombic & & & + & + \\
\hline
\end{tabular}

* +: The crystal phases exist in cement composites. 


\subsection{Formation Mechanism of Cement Hydration Crystals and Ordered Microstructure}

The above results indicate that GO nanosheets can order cement components into regular-shaped crystals and form compact microstructures during the cement hydration process. The formation mechanism mainly comprises template effects and self-assembly effects, which are shown in Figure 7. Figure 7a,b shows that GO nanosheets that exist as individual few-layered nanosheets are uniformly distributed in the cement paste by adding CCS/GO intercalation composites. Figure 7c indicates that the nascent crystals are growing on the GO nanosheets' surfaces used as the template effects. Figure 7d,e indicates that the initial crystals grow in GO nanosheets in order to form regular-shaped crystals and then continue growing to form a compact and ordered microstructure by self-assembling and self-crosslinking, as shown in Figure $7 \mathrm{f}$.

(a)
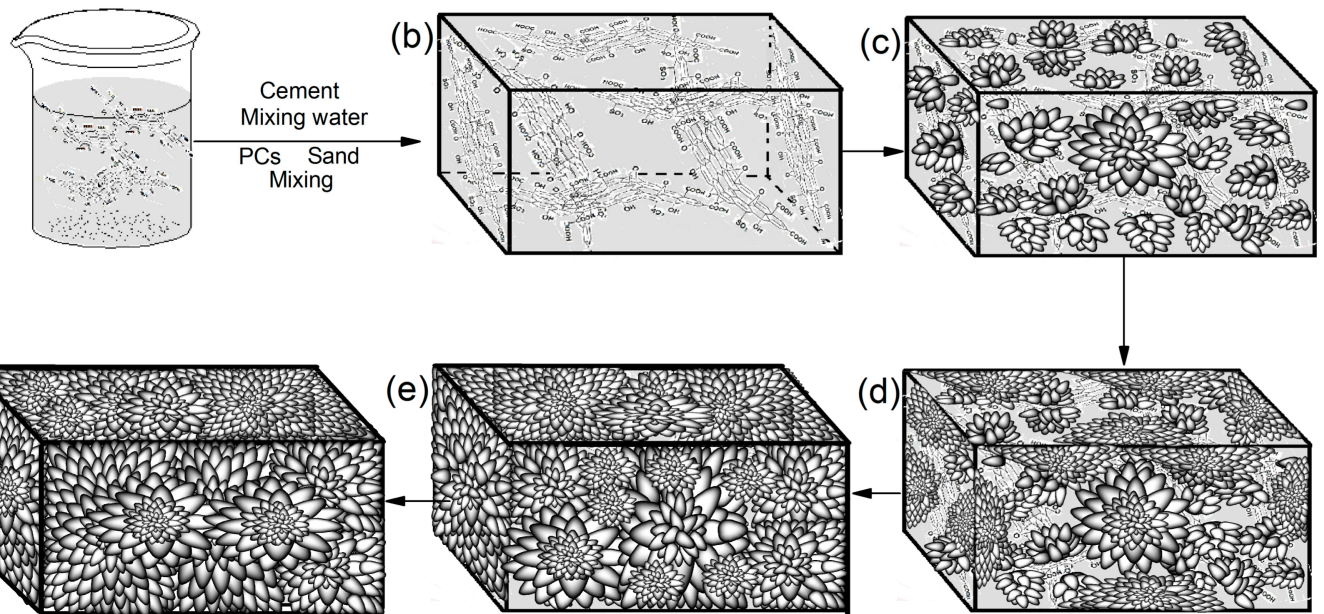

Figure 7. Forming mechanism of regular-shaped cement hydration crystals and compact microstructure. (a) CCS/GO intercalation composites; (b) Few-layered GO nanosheets uniformly distributed in cement paste; (c) The nascent crystals growing on the GO nanosheets' template; (d,e) crystals growing and began forming crosslinking structure; (f) Final compact and even microstructure.

\subsection{Mechanical Properties and Durability Parameters of GO/Cement Composites}

The compressive and flexural strengths of the GO/cement composites are shown in Table 5. The results indicate that the GO/cement composites have a higher compressive and flexural strength than that of the control samples. At 28 days, the compressive strength of GO/cement composites such as $S_{2}, S_{3}, S_{4}$ and $S_{5}$ is $151.62,175.64,166.23$ and $155.46 \mathrm{MPa}$, respectively. When compared to the control samples, the increase ratios are $42.08 \%, 64.87 \%, 56.04 \%$ and $43.11 \%$, respectively. The compressive strengths of all the GO/cement composites, at 28 days, reach the level of ultra-high-performance cement composites. Furthermore, the corresponding flexural strengths also clearly increase when compared to the control sample. At 28 days, the flexural strengths of $S_{2}, S_{3}, S_{4}$ and $S_{5}$ is $22.83,31.67$, 29.38 and $28.65 \mathrm{MPa}$, respectively. Compared with control samples, their increase ratios are $80.05 \%$, $149.76 \%, 131.71 \%$ and $154.41 \%$, respectively. The results suggest that the flexural strengths significantly increased when compared to the compressive strengths. $S_{2}, S_{3}$ and $S_{4}$ are hardened cement paste and $S_{5}$ is mortar and the results indicate that, at a $0.05 \%$ GO dosage, hardened cement paste has a higher compressive and flexural strength than mortar. From the upward trend of the strengths found between three and seven days and after 28 days, we find that the GO/cement composites have little strength at 3 days and exhibit an increase in strength after seven days and after 28 days. This may be caused by the fact that the hydration crystals are produced on day 1 and begin growing on day 3 . Growing further, they may form a perfect crosslinking structure on days 7 and 28 . The final, perfect structure would be close to completion on day 7 and fully complete on day 28 . At 60 days, the strength 
is slightly higher than at 28 days, suggesting that the formation of a perfectly compact microstructure in $\mathrm{GO} /$ cement composites is a relatively long-lasting process.

Table 5. The compressive and flexural strengths of GO/cement composites.

\begin{tabular}{ccccccccc}
\hline \multirow{2}{*}{ Samples } & \multicolumn{3}{c}{ Compressive Strength (MPa) } & \multicolumn{3}{c}{ Flexural Strength (MPa) } \\
\cline { 2 - 8 } & 3 Days & 7 Days & 28 Days & 60 Days & 3 Days & 7 Days & 28 Days & 60 Days \\
\hline $\mathrm{S}_{1}$ & 40.67 & 75.25 & 106.53 & 117.73 & 3.42 & 8.52 & 12.68 & 13.54 \\
$\mathrm{~S}_{2}$ & 32.65 & 91.56 & 151.36 & 154.62 & 7.46 & 13.54 & 22.83 & 23.47 \\
$\mathrm{~S}_{3}$ & 35.41 & 95.75 & 175.64 & 177.36 & 7.85 & 17.28 & 31.67 & 32.46 \\
$\mathrm{~S}_{4}$ & 36.23 & 98.23 & 166.23 & 168.34 & 7.31 & 16.62 & 29.38 & 29.43 \\
$\mathrm{~S}_{5}$ & 31.63 & 87.43 & 155.46 & 158.42 & 6.87 & 14.32 & 28.65 & 27.36 \\
$\mathrm{~S}_{6}$ & 22.15 & 91.56 & 108.63 & 129.63 & 5.38 & 9.98 & 11.26 & 12.42 \\
\hline
\end{tabular}

The durability of cement composites depends mainly on microstructural properties such as compactness and stability. These are usually evaluated through penetration resistance, freeze-thaw resistance, carbonation resistance, drying shrinkage and pore structure. These parameters are usually used, therefore, to evaluate the durability of cement composites. Table 6 shows the durability parameters of GO/cement composites. The results compare parameter values such as seepage height, freeze-thaw mass loss, the retention rate of a relatively dynamic elasticity modulus and carbonation depth, to those of the control samples. They suggest that the durability of GO/cement composites are remarkable improved.

Table 6. Durability parameters of GO/cement composites at 28 days.

\begin{tabular}{|c|c|c|c|c|c|c|c|}
\hline \multirow{2}{*}{ Samples } & \multicolumn{2}{|c|}{ Penetration Resistance } & \multicolumn{3}{|c|}{ Freeze-Thaw Cycles * $(\times 100)$} & \multicolumn{2}{|c|}{ Carbonation Depth (mm) } \\
\hline & Osmotic Pressure (MPa) & Seepage Height (mm) & $m_{0}(\mathrm{~g})$ & $m_{\text {loss }}(\mathrm{g})$ & $P(\%)$ & 7 Days & 28 Days \\
\hline $\mathrm{S}_{1}$ & 3.5 & 15.4 & 9837 & 0.55 & 71.52 & 3.73 & 4.94 \\
\hline $\mathrm{S}_{2}$ & 3.5 & 4.7 & 9833 & 0 & 89.5 & 2.73 & 3.23 \\
\hline $\mathrm{S}_{3}$ & 3.5 & 3.6 & 9845 & 0 & 96.53 & 0.84 & 1.84 \\
\hline $\mathrm{S}_{4}$ & 3.5 & 3.7 & 9836 & 0 & 98.76 & 0.65 & 1.35 \\
\hline $\mathrm{S}_{5}$ & 3.5 & 4.1 & 9841 & 0 & 97.65 & 0.52 & 1.62 \\
\hline $\mathrm{S}_{6}$ & 3.5 & 11.3 & 9851 & 0.45 & 73.34 & 3.53 & 4.34 \\
\hline
\end{tabular}

${ }^{*} m_{0}$ : the weight of samples before freeze-thaw experiments. $m_{\text {loss }}$ : the weight of samples after 100 freeze-thaw cycles. $P$ : the retention rate of a relatively dynamic elasticity modulus of the test samples after 100 freeze-thaw cycles.

The drying-shrinkage results of GO/cement composites are shown in Figure 8. The results indicate that the GO/cement composites of $S_{2}, S_{3}, S_{4}$ and $S_{5}$ have smaller drying-shrinking values when compared with the control samples of $S_{1}$ and $S_{6}$. When comparing $S_{2}, S_{3}, S_{4}$ and $S_{5}$, the drying-shrinkage value of $S_{3}$ is the lowest; $S_{3}$ 's GO dosage is $0.05 \%$, indicating that $0.05 \%$ is the optimal dosage and that the hydration products and their crosslinking structure are also the most compact and even. The results suggest that, when dosed at $0.05 \%$, GO nanosheets have obvious inhibitory effects on the drying shrinkage of cement composites by forming compact and even microstructures. The reason for this is that GO nanosheets can control the cement hydration products, forming stable hydration crystals and a regular microstructure through the self-assembling and self-crosslinking of crystals.

The pore structure of GO/cement composites is presented in Table 7. The results indicate that the incorporation of GO nanosheets into the cement composites has an important effect on the pore structure. All GO/cement composites from $S_{2}$ to $S_{5}$ have a smaller total pore area, median pore diameters, average diameters and porosity when compared with the $S_{1}$ and $S_{6}$ control samples. The median pore diameter and average diameter of the GO/cement composites are very close and have clearly decreased when compared with the control samples. The above results indicate that it is when the $\mathrm{GO}$ dosage is at $0.05 \%$ that the $\mathrm{GO} /$ cement composites exhibit a compact microstructure, as well as the smallest average pore diameters, total pore areas and porosity. The small pores in 
cement composites are capillary pores and mainly attributed to free water in cement gel products [43]. GO nanosheets can transform cement hydration products into regular-shaped crystals and can form a large-scale compact microstructure through crystal growth and self-crosslinking. The crystal growth phase requires a certain porosity in order to provide space for growth, during which it will decrease the porosity. A smaller porosity is beneficial to the improvement of mechanical strengths and durability [44].

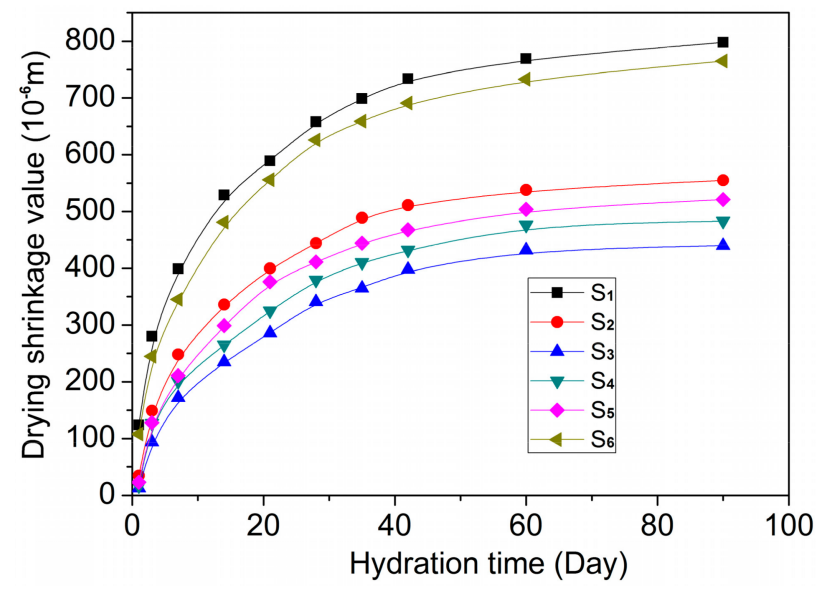

Figure 8. The variation of drying shrinkage value of GO/cement composites with hydration time.

Table 7. Pore structure of GO/cement composites at 28 days.

\begin{tabular}{|c|c|c|c|c|c|}
\hline \multirow[b]{2}{*}{ Samples } & \multicolumn{5}{|c|}{ Pore Structure of Cement Composites } \\
\hline & $\begin{array}{l}\text { Total Pore } \\
\text { Area }\left(\mathrm{m}^{2} / \mathrm{g}\right)\end{array}$ & $\begin{array}{c}\text { Median } \\
\text { Porediameter }(\mathrm{nm})\end{array}$ & $\begin{array}{l}\text { Average Pore } \\
\text { Diameter (nm) }\end{array}$ & $\begin{array}{l}\text { Apparent Density } \\
\left(\mathrm{g} / \mathrm{cm}^{3}\right)\end{array}$ & Porosity (\%) \\
\hline S1 & 24.86 & 39.42 & 55.13 & 2.21 & 23.74 \\
\hline S2 & 16.59 & 22.34 & 21.94 & 2.31 & 17.36 \\
\hline S3 & 13.68 & 15.25 & 14.67 & 2.35 & 11.25 \\
\hline S4 & 12.32 & 14.32 & 13.45 & 2.33 & 10.25 \\
\hline S5 & 15.14 & 17.67 & 19.32 & 2.35 & 15.43 \\
\hline S6 & 27.43 & 45.72 & 45.65 & 2.34 & 21.62 \\
\hline
\end{tabular}

\section{Conclusions}

(1). Original GO nanosheets, prepared by Hummers' method, are found to easily restack and aggregate in both aqueous and cement composites, a result of strong layer interactions. This causes the uneven distribution of the cement composites and a limiting of the reinforcing effects. By using CCS as a dispersant, GO nanosheets were prepared by forming CCS/GO intercalation composites; these nanosheets can exist in a few-layered form and they can uniformly spread in both aqueous and cement composites. The test results indicate that GO nanosheets can exist in aqueous composites as individual 1 to 2 layered nanosheets with a size range of 2-380 nm, while the original GO nanosheets can only exist as 7 to 16 layered nanosheets with a size range of $12-550 \mathrm{~nm}$. The results therefore indicate that CCS has a strong intercalation and dispersing capacity for GO nanosheets.

(2). The cement composites that incorporated CCS/GO with a GO dosage of $0.03 \%, 0.05 \%$ and $0.07 \%$, were prepared and all were found to have a compact and even microstructure. The outstanding feature is that the microstructures consist of regular-shaped crystals via self-crosslinking and self-interweaving. The EDS test results indicate that GO nanosheets can uniformly spread in the cement composites. The XRD results indicate that there are more cement hydration crystals in the $\mathrm{GO} /$ cement composites than in the control samples. We also found that the amorphous C-S-H gel can transform into monoclinic crystals. The results indicate that GO nanosheets are more control-effective with regards to the shaping and aggregation of cement hydration products. 
(3). At 28 days, the compressive strengths of the GO/cement composites at $\mathrm{GO}$ dosages of $0.03 \%$, $0.05 \%$ and $0.07 \%$ can reach $150 \mathrm{MPa}$. The maximum compressive and flexural strengths are 176.64 and $31.6 \mathrm{MPa}$ at a $0.05 \% \mathrm{GO}$ dosage, respectively. The increase ratios, when compared with the control samples, are $64.87 \%$ and $149.73 \%$, respectively.

(4). The durability parameters such as penetration, freeze-thaw, carbonation, drying-shrinkage value and pore structure obviously improved. The results indicate that it is possible to obtain cement composites with a compact microstructure and with high performances by introducing CCS/GO intercalation composites.

Acknowledgments: The research work was supported by the National Natural Science Foundation of China (No. 21276152) and the Innovational Industrialization Foundation of Shaanxi Province of China (No. 2016KTCL01-14).

Author Contributions: Shenghua Lv conceived of the research plan and wrote the paper. Li Sun, Jia Zhang, Xiaoqian Luo, Ying Lei and Haoyan Hu performed the experiments and analyzed the data.

Conflicts of Interest: The authors declare no conflicts of interest.

\section{References}

1. Bishop, M.; Bott, S.G.; Barron, A.R. A new mechanism for cement hydration Inhibition: Solid-state chemistry of calcium nitrilotris (methylene) triphosphonate. Chem. Mater. 2003, 15, 3074-3088. [CrossRef]

2. Lu, X.L.; Ye, Z.M.; Zhang, L.; Hou, P.; Cheng, X. The influence of ethanol-diisopropanolamine on the hydration and mechanical properties of Portland cement. Constr. Build. Mater. 2017, 135, 484-489. [CrossRef]

3. Kadam, M.P.; Patil, Y.D. Strength, Durability and Micro Structural Properties of Concrete Incorporating MS and GCBA as Sand Substitute. J. Sci. Ind. Res. India 2017, 76, 644-653.

4. Yoo, D.Y.; Kim, S.; Park, G.J.; Park, J.J.; Kim, S.W. Effects of fiber shape, aspect ratio and volume fraction on flexural behavior of ultra-high-performance fiber-reinforced cement composites. Compos. Struct. 2017, 174, 375-388. [CrossRef]

5. Zegardlo, B.; Szelag, M.; Ogrodnik, P. Ultra-high strength concrete made with recycled aggregate from sanitary ceramic wastes. The method of production and the interfacial transition zone. Constr. Build. Mater. 2016, 122, 736-742. [CrossRef]

6. Ganesh, P.; Murthy, A.R.; Kumar, S.S. Effect of nanosilica on durability and mechanical properties of high-strength concrete. Mag. Concr. Res. 2016, 68, 229-236. [CrossRef]

7. Chithra, S.; Kumar, S.R.S.; Chinnaraju, K. The effect of colloidal nano-silica on workability, mechanical and durability properties of high performance concrete with copper slag as partial fine aggregate. Constr. Build. Mater. 2016, 113, 794-804. [CrossRef]

8. Atmaca, N.; Abbas, M.L.; Atmaca, A. Effects of nano-silica on the gas permeability, durability and mechanical properties of high-strength lightweight concrete. Constr. Build. Mater. 2017, 147, 17-26. [CrossRef]

9. Asgari, H.; Ramezanianpour, A.; Butt, H.J. Effect of water and nano-silica solution on the early stages cement hydration. Constr. Build. Mater. 2016, 129, 11-24. [CrossRef]

10. Papatzani, S. Effect of nanosilica and montmorillonite nanoclay particles on cement hydration and microstructure. Mater. Sci. Technol. 2016, 32, 138-153. [CrossRef]

11. Ronquillo, G.J.B.; Madlangbayan, M.S.; Ignacio, M.C.C.D. Morphological and characterization-based verification of the properties of concrete with amorphous nanosilica synthesized from rice hull ash. Asia Life Sci. 2016, 25, 311-324.

12. Sutan, N.M.; Yakub, I.; Jaafar, M.S. Sustainable nanopozzolan modified cement: Characterizations and morphology of calcium silicate hydrate during hydration. J. Nanomater 2015, 2015, 1-6. [CrossRef]

13. Shaikh, F.U.A.; Supit, S.W.M. Mechanical and durability properties of high volume fly ash (HVFA) concrete containing calcium carbonate $\left(\mathrm{CaCO}_{3}\right)$ nanoparticles. Constr. Build. Mater. 2014, 70, 309-321. [CrossRef]

14. Mang, C.; Jason, L.; Davenne, L. Crack opening estimate in reinforced concrete walls using a steel-concrete bond model. Arch. Civ. Mech. Eng. 2016, 16, 422-436. [CrossRef]

15. Han, J.D.; Sun, W.; Pan, G.H. Monitoring the evolution of accelerated carbonation of hardened cement pastes by X-ray computed tomography. J. Mater. Civ. Eng. 2013, 25, 347-354. [CrossRef] 
16. Benabed, B.; Kadri, E.H.; Azzouz, L.; Kenai, S. Properties of self-compacting mortar made with various types of sand. Cem. Concr. Comp. 2012, 10, 1167-1173. [CrossRef]

17. Alyhya, W.S.; Kulasegaram, S.; Karihaloo, B.L. Simulation of the flow of self-compacting concrete in the V-funnel by SPH. Cem. Concr. Res. 2017, 100, 47-59. [CrossRef]

18. Cheng, Y.; Zhang, Y.; Jiao, Y. Quantitative analysis of concrete property under effects of crack, freeze-thaw and carbonation. Constr. Build. Mater. 2016, 129, 106-115. [CrossRef]

19. Jalal, M.; Mansouri, E.; Sharifipour, M. Mechanical, rheological, durability and microstructural properties of high performance self-compacting concrete containing $\mathrm{SiO}_{2}$ micro and nanoparticles. Mater. Des. 2012, 34, 389-400. [CrossRef]

20. Zhang, M.H.; Li, H. Pore structure and chloride permeability of concrete containing nano-particles for pavement. Constr. Build. Mater. 2011, 25, 608-616. [CrossRef]

21. Ghafari, E.; Ghahari, S.A.; Costa, H.; Julio, E.; Portugal, A.; Duraes, L. Effect of supplementary cementitious materials on autogenous shrinkage of ultra-high performance concrete. Constr. Build. Mater. 2016, 127, $43-48$. [CrossRef]

22. Sasi, E.A.; Peled, A. Three dimensional (3D) fabrics as reinforcements for cement-based composites. Compos. Part A Appl. Sci. Manuf. 2015, 74, 153-165. [CrossRef]

23. Afroughsabet, V.; Biolzi, L.; Ozbakkaloglu, T. Influence of double hooked-end steel fibers and slag on mechanical and durability properties of high performance recycled aggregate concrete. Compos. Struct. 2017, 181, 273-284. [CrossRef]

24. Kurad, R.; Silvestre, J.D.; Brito, J.D.; Ahmed, H. Effect of incorporation of high volume of recycled concrete aggregates and fly ash on the strength and global warming potential of concrete. J. Clean. Prod. 2017, 166, 485-502. [CrossRef]

25. Soltan, D.G.; das Neves, P.; Olvera, A.; Savastano, H.; Li, V.C. Introducing a curaua fiber reinforced cement-based composite with strain-hardening behavior. Ind. Crops Prod. 2017, 103, 1-12. [CrossRef]

26. Lago, B.D.; Taylor, S.E.; Deegan, P.; Ferrara, L.; Sonebi, M.; Crosset, P.; Pattarini, A. Full-scale testing and numerical analysis of a precast fibre reinforced self-compacting concrete slab pre-stressed with basalt fibre reinforced polymer bars. Compos. Part B Eng. 2017, 128, 120-133. [CrossRef]

27. Lv, S.H.; Ma, Y.; Qiu, C.; Sun, T.; Liu, J.; Zhou, Q. Effect of graphene oxide nanosheets of microstructure and mechanical properties of cement composites. Constr. Build. Mater. 2013, 49, 121-127. [CrossRef]

28. Lv, S.H.; Sun, T.; Liu, J.J.; Zhou, Q.F. Use of graphene oxide nanosheets to regulate the microstructure of hardened cement paste to increase its strength and toughness. CrystEngComm 2014, 16, 8508-8516. [CrossRef]

29. Chuah, S.; Pan, Z.; Sanjayan, J.G.; Wang, C.M.; Duan, W.H. Nano reinforced cement and concrete composites and new perspective from graphene oxide. Constr. Build. Mater. 2014, 73, 113-124. [CrossRef]

30. Li, X.; Lu, Z.; Chuah, S.; Li, W.; Li, Z. Effects of graphene oxide aggregates on hydration degree, sorptivity and tensile splitting strength of cement paste. Compos. Part A Appl. Sci. Manuf. 2017, 100, 1-8. [CrossRef]

31. Chu, H.; Jiang, J.; Sun, W.; Zhang, M. Effects of graphene sulfonate nanosheets on mechanical and thermal properties of sacrificial concrete during high temperature exposure. Cem. Concr. Comp. 2017, 82, 252-264. [CrossRef]

32. Dubey, N.; Rajan, S.S.; Bello, Y.D.; Min, K.S.; Rosa, V. Graphene Nanosheets to Improve Physico-Mechanical Properties of Bioactive Calcium Silicate Cements. Materials 2017, 10, 606. [CrossRef] [PubMed]

33. Ghazizadeh, S.P.; Duffour, N.T.; Skipper, M.; Billing, Y.B. An investigation into the colloidal stability of graphene oxide nano-layers in alite paste. Cem. Concr. Res. 2017, 99, 116-128. [CrossRef]

34. Cui, H.; Yan, X.; Tang, L.; Xing, F. Possible pitfall in sample preparation for SEM analysis-A discussion of the paper "Fabrication of polycarboxylate/graphene oxide nanosheet composites by copolymerization for reinforcing and toughening cement composites" by Lv et al. Cem. Concre. Comp. 2017, 77, 81-85. [CrossRef]

35. Mokhtar, M.M.; Abo-El-Enein, S.A.; Hassaan, M.Y.; Morsy, M.S.; Khalil, M.H. Mechanical performance, pore structure and micro-structural characteristics of graphene oxide nano platelets reinforced cement. Constr. Build. Mater. 2017, 138, 333-339. [CrossRef]

36. Wang, B.; Jiang, R.; Wu, Z. Investigation of the mechanical properties and microstructure of graphene nanoplatelet-cement composite. Nanomaterials 2016, 6, 200. [CrossRef] [PubMed]

37. Faria, P.; Duarte, P.; Barbosa, D.; Ferreira, I. New composite of natural hydraulic lime mortar with graphene oxide. Constr. Build. Mater. 2017, 156, 1150-1157. [CrossRef] 
38. Bastos, G.; Patiño-Barbeito, F.; Armesto, J. Nano-Inclusions Applied in Cement-Matrix Composites: A Review. Materials 2016, 9, 1015. [CrossRef] [PubMed]

39. Lu, L.; Dong, O. Properties of Cement mortar and ultra-high strength concrete incorporating graphene oxide nanosheets. Nanomaterials 2017, 7, 187.

40. Lv, S.H.; Zhang, J.; Zhu, L.L.; Jia, C.M. Preparation of cement composites with ordered microstructures via doping with graphene oxide nanosheets and an investigation of their strength and durability. Materials 2016, 9, 924. [CrossRef] [PubMed]

41. Lv, S.H.; Yang, W.Q.; Zhao, H.R.; Zhou, Q.F.; Cui, Y.Y. Effect of polyacrylate/GO nanocomposites on properties of cement paste. Mag. Concr. Res. 2016, 68, 187-196. [CrossRef]

42. Lv, S.H.; Deng, L.J.; Yang, W.Q.; Zhou, Q.F.; Cui, Y.Y. Fabrication of polycarboxylate/graphene oxide nanosheet composites by copolymerization for reinforcing and toughening cement composites. Cem. Concr. Comp. 2016, 66, 1-9. [CrossRef]

43. Appelo, C.A.J. Solute transport solved with the Nernst-Planck equation for concrete pores with 'free' water and a double layer. Cem. Concr. Res. 2017, 101, 102-113. [CrossRef]

44. Gorzelańczyk, T.; Hoła, J. Pore structure of self-compacting concretes made using different superplasticizers. Arch. Civ. Mech. Eng. 2011, 11, 611-621. [CrossRef]

(C) 2017 by the authors. Licensee MDPI, Basel, Switzerland. This article is an open access article distributed under the terms and conditions of the Creative Commons Attribution (CC BY) license (http:// creativecommons.org/licenses/by/4.0/). 